\title{
Demarcating Forest, Containing Disease: Land and HIV/AIDS in Southern Zambia ${ }^{1}$
}

\author{
Emily Frank \\ Indiana University \\ Jon Unruh \\ McGill University
}

\begin{abstract}
The ongoing HIV/AIDS pandemic in southern Africa continues to manifest itself in unexpected ways. While the consequences of the disease appear straightforward in some aspects - eg., medical, labor, cost — in other respects the repercussions, while large, are nonetheless highly nuanced and can be counterintuitive. This paper reports on the intersection of AIDS, migration, livelihood adaptation, land tenure, and forest conservation, to outline how adaptation to the pandemic has reworked significant aspects of land tenure to result in increased forest conservation in southern Zambia in the near to medium-term. The research uses a combination of ethnography, case studies, household survey and spatial analyses and finds that HIV/AIDS is used in customary legal settings to enhance land access. We also draw links to practical and theoretical implications of the relationship between AIDS, land tenure, and deforestation in Sub-Saharan Africa.
\end{abstract}

Keywords: AIDS, deforestation, forest conservation, Africa, land tenure, livelihood, adaptation, migration, Zambia

\section{Introduction}

With the highest HIV prevalence rates in the world, some scholars argue that the AIDS pandemic in southern Africa will cripple the regional economy for generations (e.g. Jayne et al., 2006; Whiteside et al, 2006; Piot et al., 2001; Ainsworth, \& Over, 1994). The number of people infected in southern Africa is hard to measure with precision, as are the disease's actual impacts on agriculture and the environment (Whiteside et al., 2006; Drimie, 2003; Jayne et al., 2006; Yamano, \& Jayne, 2004). But what is clear is that people are changing their behavior to manage the threat and impact of the disease, and that these changes fall outside the realm of sexual behavior and into decisions about access to and management of natural resources in order to secure livelihoods (Frank, 2006a). ${ }^{2}$ For this reason studies that seek to describe and measure the impact of AIDS on livelihoods and associated social structures are valuable and have contributed

\footnotetext{
${ }^{1}$ Research for this article was funded by Wenner Gren Foundation and the National Science Foundation. The authors wish to acknowledge Dr. Rod Hay for his work on the satellite imagery.

2 Although decision-making and behaviors vary importantly by context as demonstrated by Murphy (2008) in this volume, among others.
} 
significantly to our understanding of social impacts (e.g., Drimie, 2003; Jayne et al., 2006; Yamano \& Jayne 2004; Barnett et al., 1995; Bloom, \& Mahal, 1997; Curry et al., 2006). However the literature has yet to consider how people have adapted in various ways to use the pandemic to their advantage in order to better secure livelihoods; particularly in ways that would not otherwise be possible due to customary prescriptions regarding, among other issues, women and land tenure. Yet we know that African livelihoods are not static, and in most cases are indeed highly adaptable (e.g., Izumi, 2006; Wanyeki, 2003; Joireman, 1997; McCarthy et al., 2000; Hulme, \& Murphree, 2001).

This paper considers the case of southern Zambia and examines the livelihood strategies of AIDS widows with regard to land tenure which result in conservation of forest land in the near to medium-term. The topic is important because concurrently with the AIDS pandemic, Zambia is also faced with very high rates of deforestation. The neighboring states of Zambia, Democratic Republic of Congo, and Zimbabwe are among the top ten countries in the world for rates of deforestation, and Zambia ranks third behind the Democratic Republic of the Congo and Sudan in Africa in area deforested (FAO, 2001, 2007).

It is at the nexus of AIDS and rural livelihood strategies where some of the ways in which the AIDS pandemic influences forest conservation can begin to be understood. In this examination we consider how widows purposefully invoke AIDS in strategies to retain or gain control over land resources, with the unintended consequence of forest conservation in the face of increasing land pressure by migrants. As Africans seek to manage the threat of the disease and minimize economic and social risks, they pursue various strategies that call AIDS into play. In Southern Province, Zambia, one of the most important ways AIDS has been connected to forest conservation, land tenure, and management of resources most overtly, has been in questions of inheritance. When a head of household dies, household property, labor, and land (particularly uncleared land) all enter into the realm of inheritance. In rural southern Zambia, AIDS is often invoked as a way of advancing inheritance claims to these critical resources. By examining how these strategies operate, the linkages that connect natural resource management to community and individual efforts at disease management can begin to be untangled.

The findings presented here were derived from two separate research projects that took place in the same study site. The first was a household survey with a remote sensing analysis that examined migration, land tenure and deforestation. The second was an ethnographic study of contests over inheritance, and changing gender relations within the context of the AIDS pandemic. While neither study was directly seeking a link between AIDS, forest conservation, and inheritance, the link emerged when the findings of the two efforts were considered together. Here we seek to present the results of these two studies to illustrate a sequence of: 1) migration leading to increasing pressure on forest areas and resulting deforestation, which then leads to, 2) the emergence of strategies to 
retain control over forested land by male head of households, strategies which, 3) stop working as strategies with the death of the head of household, which in turn leads to, 4) the derivation of inheritance-related strategies by widows who invoke AIDS to retain lands and keep them in forest in the near to medium-term. Figure 1 illustrates this scenario and associated methodologies. Subsequent to a brief background review which assembles the context involving AIDS and natural resources, migration's influence on environmental change, and AIDS in Zambia, a description of the study site and methodological approach follows, after which the paper elaborates the sequence noted above by drawing on the literature, and presenting data from the remote sensing, household survey, and ethnographic data in order to examine how invoking AIDS presents opportunities for control over land resources, and forest conservation.

The sequential presentation of the analysis of these issues: migration and deforestation, attempts at retaining forest land, AIDS and inheritance, land tenure, and forest conservation, should be understood as reflecting a particular social setting which compel people to pursue certain strategies, in a way that makes them acceptable on a wider community level. What this paper does not seek to do is present specific statistical outcomes between migration, deforestation, AIDS, inheritance, land tenure and forests; but instead illustrates how these ongoing processes work together to create a particular perception of risk which influences decision making and subsequent natural resource management. This distinction is critical because previous studies that have sought to link land tenure and AIDS, or deforestation and AIDs, or even migration and AIDS have not focused on how decision making around resource management is altered based on local perceptions of risk to AIDS. Yet we have found that it is this perception that drives decision making and behavior change in this scenario. Local populations do not have access to the numbers of people infected, statistical rates of deforestation, or national levels of migration, and therefore, can only make informed decisions based on perceptions. One sphere in which the perceptions of these ongoing issues is most acutely manifested is through inheritance upon the death of a male head of household. Thus it is through an ethnographic examination of inheritance contests that we highlight how these issues come together to influence community resource management.

\section{Background}

\section{AIDS and natural resources}

The empirical literature on the linkages between AIDS, land tenure, and natural resources is sparse, although certain topics are receiving attention. The UN Food and Agriculture Organization (FAO) has taken the lead on understanding links between land tenure, rural livelihood security, and HIV/AIDS (FAO, 2003a, 2003b; Aliber et al., 2004; Aliber, \& Walker, 2006). As well, a growing scholarly literature seeks to articulate the connections between AIDS, rural livelihoods, and agriculture in Africa (Ainsworth et al., 1998; Barnett, \& Whiteside, 2002; Gillespie, \& Kadiyala, 2005; Mather et al., 2005). This work is important in understanding how the pandemic is affecting food production, agricultural outputs, and household security, as well as the interactions between HIV/AIDS, gender, 
and tenure security. How women intersect with land tenure systems is a particular problem in Africa, and especially acute for widows (e.g., Izumi, 2006; Quisumbing \& Otsuka, 2001; Wanyeki, 2003; FAO, 2002; FAO/IFAD/ILC, 2004). Many statutory laws lack provisions regarding women's access to land and property and the fate of these assets in inheritance (Izumi 2006). At the same time, the implementation, dissemination, and enforcement of laws that do contain such provisions are weak. As well customary laws can be significantly discriminatory with regard to women's ownership and control over land (Wanyeki, 2003; Izumi, 2006; Quisumbing, \& Otsuka, 2001).

While Jayne et al. (2006) argue that the AIDS mortality shocks occurring in particular households are actually spread across numerous households in a community, we argue that repercussions are felt still more widely and are spread across numerous communities, particularly where migrants are involved. Such broader repercussions reside within the realm of perception of risk, and attempts at maintaining or achieving community stability in the face of the pandemic. Maintaining community stability and 'harmony' is an important value intrinsic in many customary dispute resolution processes, and AIDS and its impacts are seen as one of the critical factors that can disrupt community harmony and well being. Our findings demonstrate that not only are AIDS related shocks perceived of as negative as Jayne et al. (2006) suggest, but also as opportunities, especially as a way of negotiating new claims on property. And while Jayne et al. (2006) do note that there are effects on social structures, what is not addressed is how rural communities are reorganizing social structures and social relationships, in order to maximize livelihood security beyond what would have been possible without the presence of the pandemic. It is within this latter context that strategies invoking AIDS to either gain or retain control over land and other resources during inheritance emerge.

\section{Migration's influence on environmental change and AIDS}

Pervasive rural migration in the developing world is emerging as a significant trend in environmental change scenarios and alterations in resource use systems. The migration literature has much to offer as to why migration occurs, and choices and decision-making available to migrants with regard to destination areas (e.g., Lucas, \& Stark, 1985; Massey, 1993, 1990; Massey, 1998; McGregor, 1994; Townsend, 1997; Schmeidl, 1998). Migration is recognized as a primary driver of resource degradation, and significantly complicates efforts toward conservation and sustainable development (Doos, 1994; Amacher et al., 1998). Studies on environmental outcomes of migration have examined deforestation, agriculture, the character of migrants, and the dynamics of destination areas (e.g., Amacher et al., 1998; Myers, 1997; Doos, 1994; Ghimire, 1994; IUCN, 2000; Stone, 1997). More broadly migration occupies a significant place in studies and theories involving large scale environmental change (Tucker, \& Ostrom, 2005; VanWey et al., 2005; Unruh, Cliggett, \& Hay, 2005). What this literature contributes to our own study is how migrants interact with resources and communities in their new location, and the resulting environmental consequences (e.g., Amacher et al., 1998; Myers, 1997; Doos, 1994; Ghimire, 1994; IUCN, 2000; Stone, 1997). Studies of frontier regions in Brazil 
(Caldas et al., 2007; Brondizio et al., 1994; Moran et al., 1994; Walker, Moran, \& Anselin, 2000), Mexico (Haenn, 1999) and West Africa (Stone, 1997; Nyerges, \& Green, 2000) concur that the migrant phenomenon in new land settlements includes important local level dynamics of resource access, security, and socio-political control, and requires better understanding. Migration is a primary feature of the two studies presented here (the study site is a migrant destination) and migration is directly implicated more generally in both the spread of AIDS (Anarti, 1993; Brockerhoff, \& Biddlecom, 1999; Decosas et al., 1995) and deforestation (Amacher et al., 1998; Ghimire, 1994; Moore, \& Vaughan, 1994).

Past scholarship on migration as related to AIDS has found that migration is a critically important factor in high-risk sexual behavior, with its importance varying by gender and the direction of migration (e.g., Brockerhoff, \& Biddlecom, 1999; Decosas et al., 1995; Quinn, 1994; Hunt, 1989; Nunn et al., 1995; Pison et al., 1993). Luri et al. (1997) note in an AIDS context that large-scale migration is the norm in Sub-Saharan Africa. Evian (1995) has estimated that HIV infection is 50 percent higher among migrants than nonmigrants. And Brockerhoff and Biddlecom (1999) found in Kenya that female migrants within rural areas are much more prone to engage in sexual practices favorable to AIDS transmission than non-migrant counterparts; and migrants from urban locations are more liable to practice high-risk sexual practices than rural migrants. These findings are supported by the present ethnographic work. Particularly important in this literature is disaggregating migration status into more categories than simply 'migrant' and 'return migrant.' This allows the recognition that the more complex and fluid reality produces different types of migration and migrants, with differential risks of infection. And as the present work finds, also produces differential status within community social structures. The latter point is critical within a customary framework of maintaining community harmony and well being. Lower status migrants (usually the more recent arrivals) pose less threat to overall community harmony if they are dissatisfied with resource distribution decisions. For example, results from the current study reveal that migrants who arrived before most land was allocated, or had strong family ties to the area before arrival, or migrated from an area within the same geographic region, employed different strategies for accessing land, managing threats from AIDS, and employing AIDS as a strategy to claim resources, than migrants lacking these features. But importantly, community members also recognized migration as a risk factor for AIDS, and perceived recent migrants, or migrants arriving from urban areas as particularly at risk for AIDS. As migrants from these various categories mixed into existing populations, general perceptions of overall community risk for AIDS increased.

\section{AIDS in Southern Zambia}

Like many of its regional neighbors, rates of HIV infection in Zambia are quite high, so that the virus now infects between one in five or six adults (UNAIDS, 2007). Illness and death due to the pandemic are having devastating impacts on Zambia, and the pandemic is considered the greatest obstacle in developing a robust economy (e.g., UNAID,S 2007; 
USAID, 2007; Piot et al., 2001). In examining the statistical distribution of prevalence rates in Southern Africa, rural rates of infection are considered significantly lower compared to urban rates (e.g., UNAIDS, 2004, 2007). It is argued that rural populations are often more isolated and have more limited opportunities for exposure and transmission. The most recent statistics for Zambia put rates of infection at 11.8 percent for rural populations, and 25 percent for urban populations (UNAIDS, 2007). While the trend for lower infection rates in rural areas may generally be true, there are some significant exceptions in many communities particularly where migration is concerned.

\section{Southern Zambia}

\section{Study Area and Methods}

The study area lies in a large rural region known as the Kalomo Hills Forest Area in southern Zambia (Figure 2). Kalomo Hills borders Kafui National Park (the largest park in Africa), and is in a Game Management Area (GMA) created in the colonial era. The study area is part of Kalomo district in Southern Province and includes part of Chief Cikanta's and Chief Siacetema's chiefdoms. In the early 1980's there were conflicting understandings regarding the area. While it appears that the GMA was never formally degazetted, President Kenneth Kaunda announced on national radio that the area was open for settlement and land was available. Two local Tonga chiefs (Chief Cikanta and Chief Siacetema) were eager for new settlers because larger populations in their chiefdoms increased their own power locally as well as their national profile and influence. The result are large influxes of migrants from other parts of the country who may have no historical link to the community. Chiefs, through their headmen are able to allocate land to incoming migrants in order to achieve this increase in population within their chiefdom.

The study area comprises three katengos which function as a form of municipality. Within each katengo there are a number of villages. The villages are not nucleated settlements for the most part, but rather comprise dispersed homesteads, and as such they are general village areas that we refer to as 'village units'. The three katengos are, Nkondonzobvu and Hablunugu within Chief Cikanta's chiefdom, and Nsolo within Chief Siacetema's chiefdom. The village units are organized under a headman that oversees the affairs and land distribution of a minimum of fourteen families. The study area has yet to be included in a formal census, and government intervention in the area is minimal. As such, there is little official recorded information on the area.

Geographically, the study area resides on a plateau and is dominated by moist miombo woodland. Miombo is characterized by a predominance of the genus Brachystegia growing in semi-arid tropical savanna or rocky areas (Campbell, 1996). The plateau receives higher than average rainfall for Southern Province, precipitation is regular, soil quality is good, and the area is known for its ideal farming conditions (Cliggett, 2000). In addition, there is still ample forest (albeit mostly already allocated and probably to be cleared for new fields). 


\section{Methodological approach}

Both the household survey and the ethnographic data gathering took place in the three katengos of Nkondonzobvu, Hablunugu, and Nsolo. The household survey comprised 646 randomly selected households sampled in 2005. The survey sample was randomly drawn from the total number of household heads in the katengos, and therefore includes a variety of household forms including indigenous, migrant, and female-headed. Households (including migrants) in the area comprise members from the Tonga ethnic group. The survey covered household demographics, employment history, migration history, sources of income in the household, land tenure, occupation of lands, inheritance of land, farming labor, and household wealth. The household survey was used to understand pressure on land and the 'offspring and forest security' strategy in the study area (Figure 1).

For the deforestation estimate, Landsat enhanced Thematic Mapper (TM) satellite imagery was used to identify agricultural areas during the dry season, in May and July (Figure 3). Agricultural area was assessed based on spectral signatures of bare soil during this period. Ground truthing took place in 2004 and 2005. Two TM images were used, one collected in 1986 and the other in 2000 (Path 173, Rows 71, 72). The two images underwent change detection analysis in order to reveal the extent of change in cleared areas between the two dates. The remote sensing was used to partially understand land pressure in the study area (Figure 1).

The ethnographic research took place over 10 months in 2004 with a two-month follow up in 2007. The ethnography took the form of participant observation of community life, and 55 semi-structured and unstructured interviews exploring attitudes and practices about inheritance. Community members, elders, and local leaders were asked to describe their own attitudes toward customary versus statutory inheritance practices. Particular focus was placed on examining how inheritance practices were changing, and where within the process of customary inheritance, the statutory inheritance laws were posing the most significant challenges or contestations at the community level. As well, twenty three widows in Nkondonzobvu were interviewed about their own experiences with inheritance. These interviews functioned as case studies, providing information on how customary inheritance is being enacted within the larger contested framework. Many of the widows interviewed were either undergoing, or had recently undergone inheritance negotiations regarding their own status ${ }^{3}$ (e.g. decisions about whether they were themselves going to be inherited, move households, keep or lose access to land held by a deceased spouse, etc.). In situations in which ongoing inheritance decisions were being negotiated, the kin involved in negotiating inheritance decisions on behalf of the

\footnotetext{
${ }^{3}$ Inheritance among the Tonga has customarily operated under a levirate system whereby the kin of the deceased man retain household property and offer support to surviving wives and offspring by providing them the opportunity to marry a male relative of the deceased, usually a brother or a nephew. For further discussion see Colson, (1951).
} 
deceased were also interviewed where possible. The ethnographic research was used to understand migration, pressure on land, customary inheritance practices, and the 'AIDS and inheritance' strategy (Figure 1).

\section{Results}

We present the results of the two studies in the sequence in which their events occur within the study site: migration which creates pressure on land and leads to deforestation; the emergence of strategies by heads of households to keep land allocated to early arrival migrants from being reallocated by local headmen to newly arriving migrants; the failure of these strategies when the male head of household dies; the subsequent emergence of strategies by widows who are able to invoke AIDS to avoid being inherited along with all land and property by the deceased's kin, and instead to gain control over their deceased husband's land, and keep it in forest (Figure 1). As noted earlier, these results emerged after comparing the data from two separate but related studies. The first was an ethnographic study on inheritance practices and HIV/AIDS, the second, a quantitative household survey on migration, land tenure and deforestation. When the results from these two different projects emerged, the discovery around the links between deforestation and AIDS became clear.

\section{Pressure on land: migration and deforestation}

Migration and land allocation: ethnography and the literature

The results from the ethnographic fieldwork support earlier findings that one of the more important factors that drives deforestation in southern Zambia is the significant urban-torural migration caused in large part by the continued economic stagnation in urban areas (Unruh, Cliggett, \& Hay, 2005). Lack of employment opportunities, poverty, and social instability propel many Zambians to move to rural areas where they may have extended kinship networks or historical ties (Potts, 2005; Ferguson, 1999). This is supported by a government policy that encourages people to 'return' to rural areas. As well, rural residents living in environmentally degraded areas of the country are moving to other rural areas as opposed to migrating to urban areas (Cliggett, 2000, 2003). And importantly, as the ethnographic fieldwork points out, as the urban educated young adults succumb to AIDS, their surviving spouse and offspring are returning to rural areas to reside on family homesteads so as to engage kin-based social security networks.

Migrants began to move into the study area as early as 1983 (Cliggett, 2000; Colson and Scudder, 1988). When this migration history is compared to the AIDS history, the ethnographic work found that the area became more heavily settled after the onset of the AIDS pandemic in the region. Virtually all of the residents have moved from elsewhere and have histories in other communities. Many of the residents migrated from the Gwembe Valley - several hundred kilometers away - and had tried (and often failed) to establish livelihoods 'in town' before migrating again to the study area. There are also many migrants that are moving to the area from urban locations in the Copperbelt (northern Zambia) or Lusaka, the capital (Ferguson, 1999). Thus the study area contains a 
very mobile population with many links and frequent interactions with urban life. Today there is still in-migration, but unallocated land in the area is becoming increasingly scarce (also Cliggett et al., 2007). Many migrants who were early arrivals argue that while they have a good deal of extra land still in forest, they need to keep it in forest for their sons and not have it reallocated to other migrants. Many recent migrants borrow land from a distant relative in the area, while pressing local leadership for more land to become available. Headmen are continually trying to balance the land needs of long-term migrant residents with growing sons, and the more desperate recent arrivals (Unruh, Cliggett, \& Hay, 2005).

Livelihoods for migrants are often based on a combination of subsistence and small-scale cash-crop farming (Unruh, Cliggett, \& Hay, 2005; Cliggett, 2000). Upon arrival in a new location, migrants acquire land by requesting an area from the local headman. The local leadership usually attempts to grant such requests, in part because adding people increases the political base of a headman and his chief. Such a population base is important to the chief's interaction with other chiefs and with the State, and as a result, chiefs want to allocate as much 'unused' land as feasible (Unruh, Cliggett, \& Hay, 2005). At the same time, however, the local leadership allocates more land to migrant households than is needed for near-term cultivation, due to the expectation that dependents will join the migrants in the future and the children of migrants will come of age and need their own farms, both of which contribute further to the chief's political base. This additional land, often quite large, remains in forest until there is a reason to clear it (Unruh, Cliggett, \& Hay, 2005). The link between children and future use of uncleared land is quite strong in the study area, as subsequent results demonstrate. However pressure to reallocate unused land to new migrants is also strong. Because unallocated land is now scarce in the study area, forested portions within existing land allocations are vulnerable to allegations of non-use, particularly by newly arriving migrants who need land, and who try to pressure headmen into reallocating apparently unused land. This drives a pervasive perception among local landholders that their lands are at risk for reallocation.

\section{Deforestation: satellite imagery and change detection}

The signs of in-migration in the study area are manifested in decreasing forest cover and expanding agricultural land, as observed from the ground (Unruh, Cliggett, \& Hay, 2005; Cliggett et al., 2007), and on satellite images (Figure 3). In the study area, migrants have moved into heavily wooded areas incrementally, evident on satellite imagery from 1986 compared to 2000 (Figure 3). The area presented in Figure 3 comprises the Kalomo Hills Forest Area. Satellite remote sensing work in the study area as part of the household survey research indicate that total area of cleared land for agriculture more than doubled between 1986 and 2000 (Unruh, Cliggett, \& Hay, 2005). Cultivated fields are shown to be dispersed, which reflects the manner in which land is allocated to migrants by headmen, as also confirmed by the survey fieldwork. Relatively large areas are allocated, containing comparatively small areas within them that are under active cultivation. Thus 
significant areas within allocations remain in forest. This approach to land allocation also facilitates a quicker, albeit dispersed, occupation of the landscape, than if allocations were smaller, and made for current cultivation purposes only (Figure 3). While local headmen claimed in 2004 that all land had been allocated (Cliggett et al., 2007), it is these forested areas within large allocations that are most vulnerable to reallocation to newly arriving migrants.

From the two images in Figure 3 (1986 top and 2000 bottom) an eastward to westward pattern of clearing for agriculture is evident. This is because many of the migrant locations of origin lie to the east and northeast: the Gwembe Valley, and the urban centers of Lusaka and other towns along the one north-to-south road. The area to the west of the study area has a much lower population density (Macmillan, 1997), and entry to the study area from the west is made difficult by the presence of Kafue National Park. In the 1986 image, most cleared land can be observed in the eastern third of the image. In the 2000 image, cleared land has extended westward with the exception of the westernmost quarter of the image and study area, adjacent to Kafue National Park.

The change detection analysis based on satellite imagery supports both the current ethnographic work and findings from previous research (Unruh, Cliggett, \& Hay, 2005; Cliggett et al., 2007) suggesting that the study area is experiencing significant land pressure yielding land clearing due to ongoing in-migration. It is under such conditions of significant land pressure that early migrants who have forest land, devise strategies to keep their unused land from being reallocated to newly arriving migrants (Figure 1).

\section{Strategies to retain forest land}

The 'clearing to claim'strategy

The strategy of 'clearing to claim' involves cutting the trees from most or all of an allocation - much more than needed for cultivation - in order to create a visible indication that the land is 'in use' and thus avoid allegations of non-use by newly arriving migrants seeking land, and by headmen looking for unused land to allocate to migrants (Unruh, Cliggett, \& Hay, 2005). This creates a category of land that is neither forest nor cultivated. One inadvertent outcome of this strategy is to put still greater pressure on those households with allocations still containing forest (Figure 1). As the following section describes, some with forest devise a specific strategy to keeping such land from being reallocated, and to keep it in forest, instead of pursuing a 'clearing to claim' strategy.

\section{The 'offspring and forest security'strategy}

The primary argument this strategy makes is that forest areas within allocations need to be kept in such a state because it is needed for one's children in the future. The preliminary work (key informant interviews) for the 2005 household survey first noted this strategy in the study area, and the subsequent household survey explored the strategy for the randomly selected sample. There are three aspects to the strategy of invoking the 
future well being of one's children as a strategy to keeping land and keeping it in forest. These concern the location, age, and number of children. Table 1 presents data from the survey regarding the location (on the homestead or not) and age of children with regard to the effectiveness of this strategy. From Table 1 it can be noted that the presence of children on the homestead, as opposed to away from the homestead but not the age (old enough to marry versus younger), plays a large role in keeping forest land from being reallocated. However if the children are grown and have moved to town (age and location), or have all died, the argument that forest land is needed for children becomes difficult to sustain, and forested land can be more easily reallocated. Table 2 presents data on the perspective of farmers regarding just the quantity of children connected to a household as linked to keeping land in forest. Most of the respondents ( 84 percent) felt that just simply the more children that are attached to the household, the stronger the argument is to retain land, and keep it in forest.

Thus the strategy of keeping land in forest by using the argument that it is being saved for future use by one's children (together with the physical presence of children in the household) appears to be widely accepted among the randomly selected sample. The basis for this strategy involves two fundamental components, 1) the presence of a male head of household in whom land rights are vested, and who actively makes the 'argument' (pursues the strategy), and 2) the strong customary notion that the future of one's children should be secured - as an important aspect of community well being. As a strategy however it fails when the head of household dies, and children's future security as well as that of surviving wives becomes, according to customary law, the responsibility of the inheritance process. Historically such inheritance involves the deceased husband's relatives providing an appropriate family member (generally the brother or nephew of the deceased) to 'inherit' the wives and young children, along with the property that belonged to the deceased's household (including all land) so as to care for surviving family members. However with the onset of the AIDS pandemic, the burden of taking care of the very large numbers of widows and their children as well as the stigma associated with an AIDS connection, has resulted in the considerable degradation of the 'support' aspect of this inheritance construct (Mendenhall et al., 2007; Keller, 2000; Sealey, 2003). Thus while the inheriting of property is still vigorously pursued by the deceased's relatives, the responsibility for taking care of surviving family members as a pervasive customary construct has undergone significant dissolution. This results in an increase in 'property grabbing'4 (e.g., Times of Zambia, 2005; Mendenhall et al., 2007; Keller, 2000; Sealey, 2003). Because AIDS widows are often younger women with young children, they carry less status, and often have less social power. The relatives of the deceased are able to more easily threaten these young widows with repercussions if they object to such property grabbing, as well as diminish their claims to property because the

\footnotetext{
4 Property grabbing occurs when the relatives of the deceased seize household property from the widow, often leaving widows and children destitute. Property grabbing is a problem identified in many regions of sub-Saharan Africa and has become the focus of many women's rights organizations and international NGOs.
} 
length of the marriage is often short, and fraught with illness. These factors play into emergent discourses that operate locally around the role of young women as those that spread AIDS, infecting innocent men and gaining access to their property.

In response to the disintegration of the traditional customary inheritance norms that provided for taking care of surviving widows and offspring, particularly in the wake of an AIDS related death of a household head, new strategies have emerged which seek to keep land and other property with the widow and surviving family members, thereby securing the future of children and the overall family (Figure 1). Such strategies are complex and nuanced, and are not always successful, but are nonetheless vigorously attempted and continue to develop. These strategies take advantage of local perceptions of the significant risk that AIDS poses to households and communities, and on customary moral orders that place a high value on maintaining community harmony and well being, and providing for family members after a male head of household dies. The remainder of this paper describes in some detail, from the ethnographic work, the context, perceptions, rationale, and reasoning that go into such strategies, and provides two illustrative cases where variants of the strategy were employed.

\section{The 'AIDS and inheritance'strategy}

In order to describe this strategy in some depth, the initial description is followed by an elaboration of two important supporting components, 1) migration and risk, and 2) using risk. These are then followed by two illustrative case studies.

\section{Strategy description}

Succinctly, this strategy involves widows whose husbands are suspected of having died from AIDS, actually promoting the idea that they themselves might also have AIDS, and thus that they pose a significant risk to any potential in-laws who would attempt to inherit them, their children, and the household's land and property. With the purposeful suggestion of such risk, the widow is able to express concern about the broader community, and therefore insist on not being inherited, and to instead argue that she should keep all land and property so as to be able to support her children--with security of children again being a community priority. This argument proves attractive to the deceased's relatives because it serves to alleviate the kin of the deceased from providing full material support for wife and offspring throughout a potentially long and ultimately fatal illness, while at the same time ensuring that efforts have been made to secure the future livelihood of the widow's children. While manifesting itself in various forms, the successful strategy comprises three components. First, the suspicion of having AIDS and the burden and danger that this would expose a potential inheritor's family to, creates disincentives for in-laws to pursue customary inheritance. That such an element remain as a suspicion, and not an overt, clear declaration of having the disease is important. If there is acknowledgment and clarity that the widow has the disease, then customary ostracism, sanction, and lack of support will follow, thus detracting significantly from the prospect of the strategy having success. Second, the concern expressed by a widow as to the well 
being of the wider community (protecting the community from AIDS) lends significant support to her efforts to avoid customary inheritance practices which would involve sexual cleansing 5 and the implied repercussions. Third, the widow uses the customary priority of providing for the future well being of children, as a way to have land and property of the household remain with her. In short, the customary logic is, if the widow and children are not to be inherited and looked after by a potential in-law, then the household's land and property should also not be inherited so that the widow can provide for her family. A key part of this strategy is the perceived likelihood that the widow in question may indeed have AIDS. Such a perception of likelihood comes about through broader social conditions involving migration and risk, which the next sub-section describes.

\section{Migration and risk}

As noted in the introduction, migration and AIDS operate in tandem in southern Zambia to create a perception of significant risk. In the study area many residents do not know one another's history, and perceive their neighbors to be at high risk for AIDS. They know that migrants are arriving from urban areas, and that AIDS rates are high in urban areas and high among migrating populations. So even if residents themselves are migrants, they view those around them with higher levels of suspicion than they would if they had arrived in a stable, established community. The population finds themselves living among people who have a past with which they are not connected, which is very different than 'traditional' village life. In other words they cannot be sure of fellow residents' sexual behaviors or if someone has had a spouse or partner die of AIDS before arriving in the area.

In addition to long-term migration, short term migration for commerce is also viewed to be a significant source of risk. Because of the community's proximity to Kafui National Park, Nkondonzobvu had a thriving illegal bush meat trade for years based on the park's wildlife. Before an NGO offered incentives to pursue agriculture instead of hunting, and to expel outside hunters and traders in bush meat, female bush meat traders would arrive from some distance, and often exchange sex with local hunters for goods, or raise money by brewing beer and engage in sexual liaisons with local men. Today maize and cotton companies send in buyers, and women traders in second hand clothing (e.g. Hansen, 2000) arrive with these buyers. Residents report widespread community intermingling with such traders and fear that an increased risk of exposure is brought to the community. Thus the ethnographic findings reveal that in addition to in-migration, significant trading activity contributes to a heightened perception of the exposure of the general community to AIDS (Figure 1). Watkins (2004) found that in rural communities in Malawi fear of infection is often much higher than actual rates of infection. Like in Malawi, many residents of the study area believe that significant numbers of the community could be

${ }^{5}$ Under customary Tonga inheritance, cleansing is considered essential in ridding the widow/widower of the spirit of the deceased. Sexual cleansing is widely practiced among the Tonga whereby a relative of the deceased has sexual intercourse with the widow/widower. 
infected with the virus and are observant when residents fall ill. Multiple informants in Nkondonzobvu suggested that rates of infection in their community were probably around twenty five to thirty percent, while in urban areas they thought rates of infection were more likely around sixty percent. These rates are greatly inflated compared to national statistics, but work to create a community-wide perception of severe risk.

\section{Using risk: assessment and ambiguity}

Testing and treatment centers are not readily accessible in the study area nor in most rural areas of Zambia. Assessment of the threat of AIDS is measured in the study area by alternative means, as it is elsewhere in Southern Africa where testing and treatment are not readily available or physically or socially accessible (Frank, 2006a, 2006b, 2006c). Such assessment is done by noting the number of funerals for men and women that community members attend monthly, and the types of chronic illnesses people suffer, noting in particular skin rashes, diarrhea, TB treatments, and wasting. Through these visual and social markers people assess how many people around them might be HIV positive and if they personally might be at risk. If AIDS is suspected of causing death, at a funeral (which normally lasts several days) community members will comment on how many extramarital relationships the deceased had, and with whom, comment about types and duration of illnesses, and then try to assess who else in the deceased's social circle may be at risk. Thus it is the very ambiguity about HIV status coupled with a sense that the threat of infection is pervasive, which allows AIDS to be used in a strategy within social relationships in order to claim resources.

However part of working with such relationships is the priority that specific customs not be transgressed. Because AIDS has become linked with promiscuity, and immorality, older Zambians often point to young men and women who fall sick as being victims to their own lack of respect for custom, and lack of commitment to community relationships and customary networks of social exchange. Those who clearly have AIDS can easily be categorized as dangerous and disruptive to the social order. In order to minimize such categorization, an individual suspected of being infected must frame claims to land and property within a wider context of promoting community health, well-being, harmony, and safety. If an infected person is seen as operating exclusively in her/his own selfinterest, then claims to resources, particularly in inheritance contests, will often fail and open the individual up to community scorn, ostracism, social marginalization, and economic destitution. Such a framework follows what Nyamnjoh (2001) calls 'domesticated agency' in which harmony, interconnectedness and negotiation between individual and community interest, are priorities. Because so few people know their actual status or the status of their neighbor, obliquely claiming or implying a sick status, while navigating within community priorities of group well being can provide for opportunities to effectively lay claim to land and property, if presented as balancing community and individual needs. The precise nature of such a strategy can vary, as the two cases presented below illustrate. 


\section{Illustrative case studies}

\section{Case study one: Nuria ${ }^{6}$}

Nuria's husband died in October of 2003 and she was interviewed a number of times as part of the ethnographic study, beginning only six months after her husband died. The situation regarding inheritance in this case had not been fully determined initially. Nuria suspected her husband may have died of AIDS due to the nature of his illness. She also noticed symptoms of a sexually transmitted disease in herself and worried that she may be HIV positive. Follow up fieldwork in 2007 found that Nuria was one of the first residents of Nkondonzobvu to begin taking anti retro virals (ARV's), to combat AIDS beginning mid year in 2005. Nuria and her husband were long time residents of the area, arriving and establishing a homestead in the early eighties. Like other early arrivals, they received a large plot of fertile agricultural land, and had managed a successful maize crop for many years.

It is usually at funerals that decisions about inheritance are made. How funeral rituals are performed over a series of days indicates what types of social investments the associated families have in the surviving spouses and offspring, and often indicate what type of inheritance decisions will be pursued. At her husband's funeral, Nuria's in-laws designated one of her husband's brothers to inherit her, involving sexual cleansing and marriage, as per Tonga custom. However Nuria refused to be inherited and invoked the prospect that her husband died of AIDS, and by implication she too might have AIDS, along with her Christian religious beliefs, in order to support this strategy of refusal. This move was supported by her family members present at the funeral. Her refusal to be sexual cleansed infuriated her in-laws. Subsequent to a complicated familial dispute, the brothers of the deceased forced Nuria to sign a piece of paper indicating that she had refused inheritance, and as a result her in-laws were officially relieved of any responsibility for claims of support that Nuria might place on them, such as providing food or financial aid for herself or her children, or help in resolving conflicts with community members, etc. Isolating a sick surviving spouse occurs frequently in the study area. This is because relatives of the deceased frequently want to minimize their obligation for caring for such sick in-laws due to the social and financial burden this implies. In order to further support this strategy on the part of the in-laws, the land and homestead are left with the surviving spouse. Thus in this case, when Nuria refused to be inherited, a brother of the deceased, in his role as administrator at the funeral, indicated Nuria could remain on the homestead and that all of the land and property should be left to her and her children. Because Nuria's husband was married previously, and both marriages had produced children, the argument was that the children of both wives needed to be supported from the deceased's remaining land and property assets. The brothers of the deceased concurred that leaving all the land and property with Nuria was the best way for securing a future for all of the children. Such reasoning was observed to

\footnotetext{
${ }^{6}$ The names of those involved in the ethnographic study have been changed in order to respect privacy and attend to ethical concerns.
} 
be common in the study area. It is important to note that part of this strategy-community concern regarding children's welfare and future as connected to retaining control over land - is similar to the strategy pursued by head of households described earlier as a response to increasing land pressure due to in-migration 7 .

In Nuria's case complications ensued however, including the revelation that Nuria was sexually involved with one of the younger brothers of the deceased. The result was that in-laws forced Nuria and this brother to depart from the homestead, and the land and property were distributed among these same in-laws. The in-laws argued that once she refused to be inherited on the grounds she was potentially HIV positive and a Christian, she should have stayed single so as to continue to demonstrate concern for the community's well being, thus justifying her possession of her deceased husband's land and property. But because of her relationship with one of the brothers, the in-laws were able to construe her actions as individualistic, selfish, and deceptive, in other words, not contributing to the health and well being of the community.

\section{Case study two: the Benson widows}

The two Benson widows migrated to Nkondonzobvu in 1984, early in the migration and settlement of the area. Their now deceased husband had been granted a significantly large plot of fertile, forested land. Their household had successfully engaged in farming for eighteen years prior to the husband succumbing to a long illness in 2002, that many in the community regarded as AIDS. The widows still had young children, and upon the death of their husband, they pursued a strategy to stay together, refuse customary inheritance, and keep the land allocated their late husband. Their primary intent was to maintain control of the land until their sons became old enough to marry and take over the homestead which includes the land.

In the case of the Benson widows the customary sexual cleansing ritual was substituted with a cleansing ritual known as $k u j u t a,{ }^{8}$ which involves little or no risk of transmission of AIDS. Cleansing plays a critical role in most funerals and kujuta, while considered an acceptable substitute for sexual cleansing, is definitely considered a lesser form of cleansing - indicating less interest on the part of the deceased's family in inheriting (and being responsible for) the widows. The widows claimed that kujuta was done because many people in the community think their husband died of AIDS, and actual sexual cleansing was too great a risk. However to suitably nuance the strong suspicion that the

\footnotetext{
7 While there are other cases that intentionally seek links between HIV/AIDS management and religion we did not examine it in this context. Religious identity is not a crucial identity marker in Nkondonzobvu in relation to HIV/AIDS. Nuria uses her status as a Christian only to help buttress her claims to move beyond "tradition".
}

${ }^{8}$ Kujuta literally means 'to slide' and in the context of a death cleansing ritual means that a person from the deceased's family slides their unclothed body over the unclothed bodies of the surviving spouses in order to cleanse them of the deceased's spirit. 
widows had AIDS, the widows told their in-laws that kujuta was desirable to traditional sexual cleansing because while they did not have AIDS they did not want to contract AIDS from anyone who might sexually cleanse them. In-laws would not be implicated as it is framed within larger notions of "community well being" and our research indicated that making claims to protect oneself from AIDS will not be publicly de-legitimated on a community level.

In this instance the presence of AIDS was a very real prospect, and perceived as a threat by the family of the deceased. The threat was managed by not expressing strong interest in inheriting the widows. In doing this, the in-laws allowed the Benson widows to remain on their homestead with continued control of their land--both the currently cultivated land and land kept in forest for future use by their children. Thus the Benson widows were able to use the threat of AIDS to insure that their in-laws had less claim to their land and property due to the lesser degree of social investment (and hence claim to land and property) that kujuta (as opposed to actual sexual cleansing) implies. They are also sending a clear signal to the community that they have no intention of being inherited by the family of the deceased, and therefore are willing to accept the reduced support. As well, their refusal of inheritance and purposeful statements about the danger of sexual cleansing in the context of AIDS, allows their actions to be viewed as being mindful of a healthy and socially cohesive community as opposed to individualistic and selfish. Here it is important to understand that AIDS is being utilized in a particular way that promotes community health as being directly linked to individual health, as well as household health. If the widows contract AIDS and die, the community knows it will have many more orphans to care for. Thus they have not transgressed any important community social relationship boundaries, nor have they endangered the health of their in-laws. As a result, the widows were able to retain control of their land, thus successfully keeping land in forest and for future cultivation. The Benson widows indicated that if they had agreed to be inherited it would have meant moving to a different area of Southern Province where there was significantly more pressure on land. The women noted that if they moved their children to such a location they would not have access to land, or at least guaranteed access to good land, whereas under the existing arrangement their children had a large portion of uncleared fertile land. Thus the utility of the threat of AIDS, combined with concern about community well being, including the strong link between the presence of children and the retention of forested land for their later use, was used as a strategy to prevent land from being reallocated ${ }^{9}$.

\section{Discussion and Implications}

The Zambia case illustrates the nature of the connections between AIDS, land tenure, livelihood strategies, and the environment. In the communities studied here, land holding strategies for forest management employed by early arrivals become increasingly difficult

\footnotetext{
${ }^{9}$ The events work in tandem. It operates together as a cohesive strategy and are not temporally sequential.
} 
to maintain because of the large number of newly arriving migrants. Moreover, we found that as migration levels increase, the social environment becomes more fluid, and customary norms are increasingly open to challenge and interpretation. It is precisely this environment of resource contestation where AIDS is used as a strategy to gain or maintain access to resources.

The analyses we present is certainly different than those offering quantifiable relationships of the association between population, labor, numbers of people with HIV/ AIDS and the impacts on the environment in terms of, perhaps, area cleared/cultivated. Instead, we qualitatively explore the derivation of complex and nuanced strategies designed to secure livelihoods, which result in maneuvers that incorporate the taboos and the customary discourse surrounding AIDS.

The central link with the environment is that an outcome of the strategy described here is more land being held in forest in the near to medium-term. What is new and most surprising about our results is that the taboos surrounding AIDS are used by those who have suffered AIDS-related mortality shocks, at the household level, to retain control over land, particularly unused forest land, by pursuing strategies at the community level. Also important in such strategies are the ways in which pro-individual versus procommunity actions are cast. If the strategy is seen by the wider community as overtly individualistic then a successful outcome is less likely. However if concern for community cohesion and well being is made part of the strategy, then success is more likely. Such a contrast highlights the importance of a careful strategy able to operate without transgressing major norms of customary society. It is precisely this process whereby active and creative individuals (in this case widowed women) frame their current vulnerabilities and need for resources within the balance of community and individual responsibility.

The two cases presented are not representative in the sense of providing an illustration of how all or most inheritance cases are being resolved in the area. However, these two cases provide an important finding in that they indicate a new way, acceptable to the broader community, for resolving inheritance conflicts under customary law. Thus it is currently legitimate for widows as well as the kin of the deceased to invoke AIDS or the threat of AIDS to others, as a reason to pursue a course of action with regard to resource maintenance or acquisition. In this sense, these two cases operate in a similar manner as setting a precedent in statutory law in that because they have occurred, they do in fact represent a consensus among the population in the way customary law operates in a context being shaped and reshaped by AIDS, and are therefore seen as broadly legitimate. In the cases presented here, we see clearly that AIDS has become a new part of the larger moral and social domain that is incorporated into local decision making regarding resource allocation. If these cases were mere anomalies the social support observed would not have been so widespread. In addition, decisions would have likely been overturned or positions changed over time. It has not happened in these cases. 
Thus while other strategies exist for keeping control over land(s) ('clearing to claim,' 'offspring and forest security'), the adaptability of smallholder livelihoods in rural Zambia illustrates that AIDS related strategies are derived, but are not always predictable, and do not always draw on conventional conservation or land tenure notions and concepts, or use these in conventional ways.

Our findings support other work that articulates a highly nuanced association between individuals, households, communities and AIDS. Jayne et al. (2006) look at variability in community resilience to the impacts of AIDS. Lurie et al. (1997) examine patterns of sexual networking on AIDS transmission. And Watkins (2004) looks at strategies of abstinence, fidelity, and consistent condom use along with partner selection, divorce, and renewed religious commitment. What this literature does not describe is the ability of livelihoods to adapt to AIDS in ways that might be seen as opportunities. Here we reach beyond tenure security and agricultural production to understand how the categories of widow, illness, community security, and inheritance are being reconceptualized to manage the impact of the pandemic. And in turn, how the reconceptualization of categories and emergence of new strategies affects natural resource management and allocation.

One of the contributions of this paper is to suggest areas for further inquiry. Important to such inquiry is understanding that the category 'migrant' is far too broad to be useful in understanding interactions between migration, environment, land tenure, AIDS, and customary law. In the two cases presented above, attempts at invoking AIDS as a means of retaining land were employed by early arriving migrants, who are a separate category than late arriving migrants. Both sets of widows were raising children who were born after the widows initially migrated to the area. The widows' comparatively early arrival also meant they had developed well established networks within the community. Arguably, if a late arrival who was not perceived as being embedded enough within community networks, had attempted a similar strategy, invoking AIDS might have not had the same results. Instead, widows of more recent arrivals would likely be compelled to return from where they came, in order to maintain community harmony and well being. Still, none of these assertions can be certain without further research. A deeper understanding is needed regarding how migrants construct categories and classifications among themselves, and in turn how this fits into larger understandings of community stability, integrity, and overall community harmony and well being. As well, if AIDS were to be employed in an overtly opportunistic way (e.g. with openly sick families migrating to the area to obtain land, and then a head of household succumbing to illness and his widow then claiming land) community response might be different. In the end, we argue that since the interrelationships between AIDS, land tenure, and resource management operate largely within the realm of perception perception of rights, perception of risk, perception of security - examination of the influence of AIDS on these interrelationships should carefully and critically consider the operative role of perceptions in the management of the environmental aspects of the AIDS pandemic. 


\section{Bibliography}

Ainsworth, M., \& Fransen, L., Over, M. (eds.) (1998). Confronting AIDS: evidence from the developing world. Brussels: European Commission.

Ainsworth, M., \& Over, M., (1994). AIDS and African development. World Bank Research Observer, 9, 203-240.

Aliber, M. \& Walker, C. (2006). The impact of HIV/AIDS on land rights: perspectives from Kenya. World Development, 34, 704-727.

Aliber, M., Walker, C., Machera, M., Machau, P., Omondi, C., \& Kanyinga, K. (2004). The impact of HIV/AIDS on land rights, case studies from Kenya. Cape Town, HSRC Publishers.

Amacher, G.S., Cruz, W., Gerbner, D., \& Hyde, W.F. (1998). Environmental motivations for migration: population pressure, poverty and deforestation in the Philippines. Land Economics, 74, 92-101.

Anarti, J. (1993). Sexuality, migration, and AIDS in Ghana - a socio-behavioural study. Health Transition Review, 3, 45-67.

Barnett, T., \& Whiteside, A. (2002). AIDS in the twenty-first century: disease and globalization. Basingstoke, UK, Palgrave Macmillian.

Barnett, T., Tumushabe, J., Bantebya, G., Ssebuliba, R., Ngasongwa, J., Kapinga, D., Ndelike, M., Drinkwater, M., Mitti, G., \& Haslwimmer, M. (1995). Field report: the social and economic impact of HIV/AIDS on farming systems and livelihoods in rural Africa: some experience from Uganda, Tanzania, and Zambia. Journal of International Development, 7, 163-176.

Bloom, D., \& Mahal, A. (1997). Does the AIDS epidemic threaten economic growth? Journal of Econometrics, 77, 105-124.

Brondizio, E., Moran, E., Mausel, P., \& Wu, Y. (1994). Land use change in the Amazon estuary: patterns of Caboclo settlement and landscape management. Human Ecology, 22, 249-279.

Brockerhoff, M., \& Biddlecom, A. (1999). Migration, sexual behavior and risk of HIV in Kenya. International Migration Reivew, 33, 833-856.

Caldas, M., Walker, R., Arima, E., Perz, S., Aldrich, S., \& Simmons, C. (2007).

Theorizing land cover and land use change: the peasant economy of Amazonian deforestation. Annals of the Association of American Geographers, 97, 86-110. 
Campbell, M. (1996). The Miombo in transition: woodlands and welfare in Africa. Center for International Forestry Research (CIFOR). Bogor, Indonesia.

Cligget, L., Coleson, E., Hay, R., Scudder, T., \& Unruh, J. (2007). Chronic uncertainty and momentary opportunity: a half century of adaptation among Zambia's Gwembe Tonga. Human Ecology, 35, 19-31.

Cliggett, L. (2003). Male wealth and claims to motherhood: gendered resource access and intergenerational relations in the Gwembe Valley, Zambia. In G. Clark (Ed.), Gender in Economic Life: Annual Readings in Economic Anthropology. Walnut Creek, Alta Mira Press.

Cliggett, L. (2000). Social components of migration: experiences from Southern Province, Zambia. Human Organization, 59, 1-26.

Cligget, L., Colson, E., Hay, R., Scudder, T., \& Unruh, J. (2007). Chronic uncertainty and momentary opportunity: a half century of adaptation among Zambia's Gwembe Tonga. Human Ecology, 35, 19-31.

Colson, E. (1951) "The Plateau Tonga of Northern Rhodesia”. M. Gluckman and E. Colson (Eds.) M. Gluckman and E. Colson. In Seven Tribes of British Central Africa. London, Manchester University Press.

Colson, E., \& Scudder, T.(1988). For prayer and profit: The ritual, economic and social importance of beer in Gwembe from 1950-1982. Palo Alto, Stanford University Press.

Curry, J., Wiegers, E., Garbero, A., Stokes, S., \& Hourihan, J. (2006). Gender, HIV/AIDS and rural livelihoods: micro-level investigations in three African countries. UNU-WIDER Research Paper No. 2006/110.

Decosas, J., Kane, F., Anarti, J., Sodji, K., \& Wagner, H. (1995). Migration and AIDS. Lancet, 346, 826-828.

Drimie, S. (2003). HIV/AIDS and land: case studies from Kenya, Lesotho, and South Africa. Development in Southern Africa, 5, 647-658.

Doos, B.R. (1994). Environmental degradation, global food production, and risk for large-scale migrations. Ambio, 23, 124-130.

Ferguson, J. (1999). Expectations of modernity; myths and meanings of urban life on the Zambian Copperbelt. Berkeley, California, University of California Press. 
Food and Agriculture Organization of the United Nations, International Fund for Agricultural Development, International Land Coalition (FAO/IFAD/ILC) (2004). Rural women's access to land and property in selected countries. FAO/IFAD/ILC, Rome.

Food and Agriculture Organization of the United Nations (FAO) (2003a). HIV/AIDS and Agriculture: impacts and responses, case studies from Namibia, Uganda and Zambia. Document TC/D/5145E/1/3.04.400. FAO, Rome.

Food and Agriculture Organization of the United Nations (FAO) (2003b). Mitigating the impacts of HIV/AIDS on food security and rural poverty; results of a multi-stakeholder meeting and outcomes of subsequent strategy development. FAO, Rome.

Food and Agriculture Organization of the United Nations (FAO) (2002). Gender and access to land. FAO Land Tenure Studies 4. FAO, Rome.

Food and Agriculture Organization of the United Nations (FAO) (2001). Tropical countries continue to lose forests at high rate: Zambia. State of the World's Forests, FAO, Rome.

Food and Agriculture Organization of the United Nations (FAO) (2007). Table 2, forest area and area change. State of the World's Forests, FAO, Rome.

Frank, E. (2006a). Negotiating futures in the time of AIDS: inheritance conflicts in Southern Province Zambia. Ph.D. Dissertation, Indiana University.

Frank, E. (2006b). AIDS identities: becoming positive in Zambia. Presented on November 19, at the American Association of Anthropology Meetings in San Jose California.

Frank, E. (2006c). AIDS and the Transformation of Ethnography in Southern Africa. Anthropology News, 47, 3.

Ghimire, K. (1994). Refugees and deforestation. International Migration, 32, 561-569.

Gillespie, S., \& Kadiyala, S. (2005). HIV/AIDS and food and nutrition security: from evidence to action.Food Policy Review 7, International Food Policy Research Institute, Washington DC.

Haenn, N. (2002). Nature Regimes in Southern Mexico: A history of power and environment. Ethnology 41:1, 1-26.

Hansen, K. (2000). Salaula: The World of Secondhand Clothing and Zambia. University of Chicago Press, Chicago. 
Hulme, D., \& Murphree, M. (2001). African wildlife and livelihoods: the promise and performance of community conservation. Heinemann/James Curry, Oxford UK.

Hunt, C. (1989). Migrant labor and sexually transmitted disease: AIDS in Africa. Journal of Health and Social Behavior, 30, 353-373.

IUCN (2000). IUCN-CEESP environment and security task force briefing. Presented at the World conservation Conference, Amman.

Izumi, K. (2006). Reclaiming our lives: HIV and AIDS, women's land and property rights and livelihoods in southern and East Africa - narratives and responses. HSRC Press, Cape Town.

Jayne, T., Chapoto, A., Byron, E., Ndiyoi, M., Hamazakaza, P., Kadiyala, S., \& Gillespie, S. (2006). Community-level impacts of AIDS-related mortality: panel survey evidence from Zambia. Review of Agricultural Economics 28, 440-457.

Joireman, S. (1997). Institutional Change in the Horn of Africa: the Allocation of Property Rights and Implications for Development. PhD Dissertation, Department of Political Science, University of California, Los Angles.

Keller, B. (2000). Women's access to land in Zambia. Task Force on Women's Access to Land. Swede Survey

Lucas, R., \& Stark, O., (1985). Motivations to remit: evidence from Botswana. Journal of Political Economy, 93, 901-918.

Lurie, M., Harrison, A., Wildinson, D., \& Abdool Karim, S. (1997). Circular migration and sexual networking in rural KwaZulu/Natal: implications for the spread of HIV and other sexually transmitted diseases. Health Transition Reivew, 7, 17-27.

Massey, D. (1990). The social and economic origins of immigration. Annals of the American Academy of Political and Social Science, 510, 60-72.

Massey, D., (1993). Contemporary theories of international migration. Population and Development Review, 19, 431-466.

Massey, D., (1998). Worlds in motion: understanding international migration at the end of the millennium., Oxford University Press, Oxford, UK.

Mather, D., Donovan, C., Jayne, T., Weber, M., Mazhangara, E., Bailey, L., Yoo, K., Yamano, T., \& Mghenyi, E. (2005). A cross country analysis of household responses to 
adult mortality in rural sub Saharan Africa: Implications for HIV/AIDS mitigation and rural development policies. MSU International Development Working Paper No 82, East Lansing: Michigan State University.

McCarthy, N., Swallow, B., Kirk, M., \& Hazell, P. (2000). Property rights, risk, and livestock development in Africa. International Livestock Research Institute, Nairobi, and International Food Policy Research Institute, Washington DC.

McGregor, J., (1994). Climate change and involuntary migration: implications for food security. Food Policy, 19, 120-132.

Mendenhall, E., Muzizi, L., Stephenson, R., Chomba, E., Ahmed, Y., Haworth, A., \& Allen, S. (2007). Property grabbing and will writing in Lusaka Zambia: an examination of wills in HIV-infected cohabiting couples. AIDS CARE. 19, 369-374.

Moore, H., \& Vaughan, M. (1994). Cutting down trees: gender, nutrition, and agricultural change in Northern Province of Zambia, 1890 - 1990. James Currey, London.

Moran, E.F., Brondizio, E., Mausel, P., \& Wu. Y. (1994). Integrating Amazonian vegetation, land-use and satellite data. BioScience, 44, 329-339.

Myers, N. (1997). Environmental refugees. Population and Environment, 19, 167-182.

Nunn, A., Wagner, H., Kamali, A., Kengeya-Kayondo, J., \& Mulder, D. (1995). Migration and HIV-1 seroprevalence in a rural Ugandan population. AIDS, 9, 503-506.

Nyamnjoh, F (2001). Delusions of development and the enrichment of witchcraft discourses in Cameroon. In H. Moore, \& T. Sanders (Eds.), Magical interpretations, material realities: modernity, witchcraft and the occult in postcolonial Africa. Routledge, London.

Nyerges, A.E., \& Green, G.M. (2000). The ethnography of landscape: GIS and remote sensing in the study of forest change in West African Guinea savanna. American Anthropologist, 102, 271-290.

Piot, P., Bartos, M., Ghys, P.D., Walker N., \& Schwartlander, B. (2001). The global impact of HIV/AIDS. Nature, 410, 968-973,

Pison, G., Le Gueno, B., Lagarde, E., Enel, C., \& Seck, C. (1993). Seasonal migration: a risk factor for HIV in rural Senegal. Journal of Acquired Immune Deficiency Syndromes, 6, 196-200. 
Potts, D. (2005). Counter-urbanization on the Zambian Copperbelt? interpretations and implications." Urban Studies, 42, 583-609.

Quinn, T. (1994). Population migration and the spread of types 1 and 2 Human Immunodeficiency Viris. Proceedings of the National Academy of Sciences, 91, 2407-2414.

Quisumbing, A., \& Otsuka, K. (2001). Land, trees, and women: evolution of land tenure institutions in western Ghana and Sumatra. International Food Policy Research Institute, Research Report 121, Washington DC.

Macmillan (1997). Basic education atlas of Zambia. Macmillian (Zambia), Lusaka.

Sealey, G. (2003). African widows left destitute by relatives snatching property. Christian Science Monitor, May 13, 2003.

Schmeidl, S., (1998). Comparative trends in forced displacement. In Hampton, J. (Ed.), Internally displaced people: a global survey. Earthscan Publications, London.

Stone, G.D. (1997). Predatory sedentism: intimidation and intensification in the Nigerian savanna. Human Ecology, 25, 223-242.

Times of Zambia (2005). HIV/AUIDS impacts subjects women in Property Grabbing. Staff reporter. September 12

Townsend, N. (1997). Men, migration, and households in Botswana: an exploration of connections over time and space. Journal of Southern African Studies, 23, 405-420.

Tucker, C., \& Ostrom, E. (2005). Multidisciplinary research relating institutions and forest transformations. In E. Moran, \& E. Ostrom (Eds.), Seeing the forest and the trees: human-environment interactions in forest ecosystems, MIT Press, Cambridge, MA, USA.

UNAIDS (2007). Zambia: country situation analysis.” www.unaids.org/en/

Regions Countries/Zambia.asp. Last accessed March 8, 2007.

UNAIDS (2004). AIDS epidemic update by region. www.unaids.org

Unruh, J., Cliggett, L., \& Hay R. (2005). Migrant land rights reception and 'clearing to claim' in Sub-Saharan Africa: a deforestation example from southern Zambia. Natural Resources Forum, 29, 190-198. 
USAID (2007). HIV/AIDS development challenges. Washington DC, United States Agency for International Development, Zambia Country Office. www.usaid.gov/zm/hiv/ hiv.htm Last accessed on March 8, 2007.

VanWey, L., Ostrom, E., \& Meretsky, V. (2005) Theories underlying the study of humanenvironment interactions.

In E. Moran, \& E. Ostrom (Eds.), Seeing the forest and the trees: human-environment interactions in forest ecosystems, MIT Press, Cambridge, MA, USA.

Walker, R., Moran, E., \& Anselin, L. (2000). Deforestation and cattle ranching in the Brazilian Amazon: external capital and household processes. World Development, 28, 683-700.

Wanyeki, L. (2003). Women and land in Africa: culture, religion and realizing women's rights. Zed Books, Ltd, London.

Watkins, S. (2004). Navigating the AIDS epidemic in rural Malawi. Population and Development Review, 30, 673-705.

Whiteside, A., Barnett, T., George, G., \& van Niekerk, A. (2006). Through a glass darkly: data and uncertainty in the AIDS debate. In A van Niekerk (Ed.), Ethics and AIDS in Africa: the challenge to our thinking. Left Coast Press, Walnut Creek, CA.

Yamano, T., \& Jayne, T. (2004). Measuring impacts of working-age adult mortality on small-scale farm households in Kenya. World Development, 32, 91-119. 